\title{
Correction to: Inverse transformation based weighted fusion for face recognition
}

\section{Runda Qian ${ }^{1}$}

Published online: 5 July 2018

(C) Springer Science+Business Media, LLC, part of Springer Nature 2018

\section{Correction to: Multimed Tools Appl (2018) \\ https://doi.org/10.1007/s11042-018-5987-4}

In the original publication, the Equation 18 and its citation was incorrectly numbered as Equation 13. The original article has been corrected.

Publisher's Note Springer Nature remains neutral with regard to jurisdictional claims in published maps and institutional affiliations.

The online version of the original article can be found at https://doi.org/10.1007/s11042-018-5987-4

Runda Qian

qianrunda@163.com

1 School of Technical Physics and Optoelectronic Engineering, Xidian University, Xi'an 710071 Shaanxi, China 